\title{
Die Leidenschaften
}

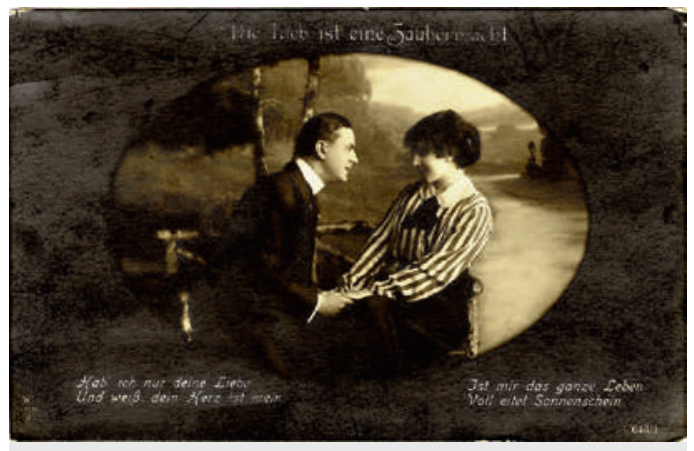

Die Liebe ist eine Zaubermacht.

Postkarte, (c) Deutsches Hygiene-Museum Dresden.
Die Ausstellungsmacher haben sich viel vorgenommen. Wie stellt man Emotionen dar? Das Thema wird als Stoff eines Dramas begriffen, dargestellt in fünf Akten auf einer Bühne, die in einer Folge von Räumen zu durchschreiten ist. Durch ein Theaterfoyer mit gerafftem, rotem Vorhang erleben die Besucher Exposition, Konflikt, Höhepunkt, Wendung und Auflösung im gleichbleibenden Bild einer Wohnung. Verschiedene Stilrichtungen und Designer-Epochen sind kombiniert, durch Verschiebung, Zerstörung und Verzerrung ändert sich thematisch der Gefühlshaushalt. Bilder und Metaphern verkörpern die Leidenschaft, lassen Dichter, Philosophen und Wissenschaftler zu Wort kommen. Chaos und Zerstörung finden wieder eine Ordnung, Erziehung, Religion, Arbeit, Sexualität, Ehe, Medizin, Hygiene, Recht und Freizeit regulieren das bedrohte, soziale Zusammenleben. Elf Szenen stellen Basisemotionen dar: Liebe, Begierde, Neid, Zorn, Angst, Scham, Ekel, Hass, Trauer, Freude und Staunen. In der letzten Abteilung geht es um Mitleid und Empathie, das Drama geht zu Ende, der Betrachter sieht die Wohnung auf der Gartenbank von aussen, drinnen herrscht ein gebändigtes Miteinander, der Vorhang fällt.

Fast wachsen einem die vielen Exponate über den Kopf, es wimmelt von Anspielungen, Hinweisen, grossen und kleinen Geschichten. Das Drama braucht Vertiefung, Ruhepausen und Nacharbeit, wenn es nicht zum Irrgarten geraten soll. Das Denkmaterial ist riesig. Wir sind Herr im Hause und sind es nicht. Viel Falsches ist in die Konzepte der Affekte eingegangen.

Wir können nicht entscheiden, nicht mehr zu fühlen, wir sind Subjekt und Objekt der Gefühle, wir haben sie, und sie haben uns, sie sind das Fenster zur Welt. Leidenschaften überwältigen, wir können uns in der Ekstase verlieren, wir erleiden Zustände des Gefühls und des Körpers. Doch wir können über Gefühle sprechen. Alles Fühlen und Spüren geht im Bewusstsein auf. Die Sprache, selber sinnlich und emotional, wird zu dem, wovon sie spricht. Sie ist Grammatik, Klang, Ausdruck und Organ, eine Verleiblichung der Gefühle, ein Mit-Fühlen. In einem klugen Vorwort beschreibt der Philosoph Hartmut Böhme im Begleitbuch zur Ausstellung die Phänomenologie der Gefühle, Leidenschaften und Sinne. Die Sprache und ihre Geschichte nennt er das überindividuelle Archiv von Gefühlen und sinnlichen Wahrnehmungen. Das grösste Museum der Welt, eine historische Kollektivarbeit, riesig, uralt, Medium der Reflexion und Medium der Verwandlung. Es sei eine der seltsamsten Konstruktionen der Philosophie, dass man im reinen Denken sich der Existenz versichern könne. Descartes' Cogito, ergo sum hat der Neuroforscher Antonio Damasio in unserer Zeit überzeugend widerlegt. Denken ist ein leiblich spürbarer Prozess, begleitet vom Fluss der Gefühle. Johann Gottfried Herder (17441803) fand dafür die richtige Formel: «Ich fühle mich! Ich bin!»

Die Exposition hat ein gewaltiges Bild- und Zitatenmaterial zusammengetragen. Der Gang mäandert durch die Kulissen wechselnder Wohnungseinrichtungen und endet in einem stillen Raum, altmodisch mit Plüsch ausstaffiert, mit gerafften Vorhängen, Spiegeln und Sitzbänken längs der Wand. Die Bilderflut bleibt ausgesperrt, das eigene Gefühlschaos findet Ruhe, die Reflexion beginnt ihre Verdauungsarbeit. Die vitalsten, gefährlichsten und dramatischsten Emotionen liegen hinter uns. Das begehbare Bühnenbild endet mit einem hoffnungsvollen Schlusspunkt. Ende gut, alles gut, es ist der Mensch doch nicht so antiquiert, wie der Kulturkritiker Günther Anders beklagte. Oder haben Transhumanisten Recht, wenn sie im Cyborg der Zukunft den Übermenschen herbeireden? Haben Gefühle in der Zukunft noch Platz, wenn sich eine neue Elite an den besten Universitäten der Welt der künstlichen Intelligenz verschreibt? Sind unsere Spiegelneuronen die vorläufig letzte Chance, auf eine Fähigkeit nicht nur als individuelles, sondern auch und vor allem als gesellschaftliches Subjekt zu handeln? Das Hygienemuseum in Dresden hat einmal mehr das Menschsein auf eine überaus fruchtbare und anspruchsvolle Weise in den Mittelpunkt gestellt. Auch wem keine Zeit bleibt, bis Ende des Jahres die Stadt an der Elbe zu besuchen, findet im reich bebilderten und absolut unentbehrlichen Ausstellungsband einen guten Ersatz für diese originelle Machart einer verpassten Aufführung. Das Begleitbuch [1] kompensiert das Verpasste mit einer fast unerschöpflichen Fallsammlung zum Thema Leidenschaften.

Erhard Taverna

1 Catherine Nichols C, Staupe G (Hrsg.). Die Leidenschaften - Ein Drama in fünf Akten. Göttingen: Wallstein Verlag; 2012. (ISBN 978-3-8353-1078-0)

Deutsches Hygienemuseum Dresden, Besucherservice: 00493514846400 service[at]dhmd.de 